\title{
Increasing Stiffness of Constructions through Application of Enhancing Elements
}

\author{
Branko TADIC, Marija MATEJIC, Goran SIMUNOVIC, Milan KLJAJIN, Vladimir KOCOVIC, Bojan BOGDANOVIC, Djordje VUKELIC
}

\begin{abstract}
Presented in this work is a study on construction stiffness, based on examination of their neutral lines for various cross-section geometries and different force magnitudes. Investigations were conducted both through numerical simulations and experimentally. The results of numerical simulations indicate that stiffness enhancement reduces deflection in the range of $41-52 \%$, while the experimental tests showed the reduction of $42-54 \%$. Also reviewed is comparative analysis between the stiffness results obtained by numerical analyses and experiments, which showed high degree of their compliance. The deviations between the results offered by the two methods are 1-3\%, on average, while in the worst case, which occurs in just a couple of points, the deviation equals $10 \%$. This study revealed significant increase of element stiffness, which was obtained by employment of additional stiffness enhancing elements.
\end{abstract}

Keywords: enhancing element; stiffness

\section{INTRODUCTION}

All elements which establish contacts within a machining system exert significant influence on the geometry and machining accuracy of workpiece [1]. There are numerous forces and torques which act upon workpiece during machining. Through fixture elements which interface the workpiece, their influence is transferred onto the other elements of the machining system. This causes displacements and deformations of the elements of the machining system, which, consequentially, leads to deviations from nominal tolerances and reduces machining accuracy [2]. Deformations of machining system components, as well as their contact interfaces, significantly impact system stability, i.e., machine tool [3], cutting tool [4], fixture [5], and workpiece [6]. During the process, clamping forces and torques are being transferred onto all other elements of the machining system. Within this load transfer chain, contact interfaces between workpiece and other system elements, most often represent the most sensitive link [7]. In general, all elements of machining system are required to have high stiffness, i.e., low compliance. The stiffness (k) can be defined as the relationship between the force $(F)$ which loads the appropriate structures and displacement $(x)$ caused by this force, i.e. as: $k=F / x$. Compliance $(p)$ is the reciprocal value of stiffness, i.e. $p=1 / k=x / F$.

Stiffness of basic mainframe and particular elements has been in the focus of a number of studies. Salgado et al. [8] elaborated the investigation of the stiffness of the system formed by a machine tool, shank, tool holder, collet and cutting tool. They evaluated the stiffness of each of the existing elements between the machine bed and the tool tip. The results have shown that stiffness of the slender and flexible tools is 15 times lower than that of the machine and tool holder system. Agapiou [9] developed a methodology for estimating joint stiffness parameters for a tool holder - spindle interface. Based on the results, the stiffness at the tip of the cutting tool also depended on the stiffness of the tool, the spindle geometry and bearings, the housing, and the overall machine structure. Zheng et al. [12] proposed an FE model to predict fixture unit stiffness by introducing nonlinear contact elements on the contact surface between fixture components. Nonlinearity was defined using the penalty function method and was solved by the modified Newton-Raphson procedure. Zheng et al. [11] presented an experimental investigation to estimate the contact stiffness between fixture elements. There was a linear dependence between contact stiffness and the preload on the contact surfaces. Feng et al. [12] represented the stiffness behaviour of jaw-chucks with two chuck-specific stiffness parameters (radial stiffness and bend stiffness of chuck unit) and two jaw-specific stiffness parameters (radial stiffness and bend stiffness of the top jaw unit). Also, they developed an analytic model for the determination of the dynamic clamping force of jawchucks during high-speed turning that took into account the influence of the stiffness behaviour of the chuck and workpiece. Mei et al. [13] developed a suppression method based on a magnetorheological fluid-controlled boring bar for chatter suppression. The magnetorheological fluid, which can change stiffness consecutively by varying the strength of the applied magnetic field, was applied to adjust the stiffness of the boring bar and suppress chatter. Matsubara et al. [14] investigated the uncertainty of the stiffness of a rotating spindle using a non-contact excitation method. Noncontact excitation tests of a machine tool spindle were conducted to predict chatter conditions and monitor oscillation under regenerative force feedback. Tadic et al. $[15,16]$ designed high-stiffness tool for ball burnishing. High-stiffness burnishing tool can significantly increase quality surface finish, dimensional and geometrical accuracy. Shi et al. [17] described a new top-down design method for the stiffness of machine tools that considered the entire machine stiffness to guarantee the stiffness. A new stiffness characterisation using the stiffness coefficients for characterising the stiffness of the structural parts and the functional units was proposed. The deformation model was established based on multibody system theory, and the equations of the stiffness coefficients for the deformations of the components were established based on the simultaneous equations of the static equilibrium equations, the deformation compatibility equations and the physical equations. Gao et al. [18] proposed a novel low-order stiffness matrix model to model the static stiffness field of the machining space and reduce the machining errors. The technological parameters based on the locations were plugged into the stiffness model, with a prediction of the machining errors. Barbato et al. [19] developed a new method for contact 
stiffness evaluation. A mathematical model was developed in order to perform a systematic analysis of factors contributing to the uncertainty of indentation modulus estimation using GUM guidelines, enabling quantitative evaluation of the main contributions such as contact stiffness, frame compliance and indenter area function. Archenti and Nicolescu [20] proposed a novel methodology to assess individual joint errors in machine tools using an equivalent stiffness concept. The equivalent stiffness approach identified and calculated the contribution of joint error sources to the total deviation measured between tool holder and workpiece under loaded conditions. Liao et al. [21] proposed a method to determine the contact stiffness and contact force of shrink-fit tool holder joint. Based on Hertz contact theory and fractal geometry theory the relationship between the contact stiffness and the normal contact load was deduced. The identified contact stiffness was incorporated into the finite element model of the tool-holder, which was then used to predict the tool point frequency response function. Matejic et al. [22] developed a novel mounting frame fixtures. FEM analysis was used to compare the stiffness of mounting frame modular fixtures to their conventional counterparts. Stiffness enhancing elements were applied to increase stiffness.

In contrast to previous investigations, this study is focused on increasing the stiffness of existing, cylindrical elements, using additional box-shaped elements. These additional, stiffness enhancing elements should contribute to a more significant stiffness of other elements, thus contributing to higher accuracy and surface quality, with enhanced productivity and minimal additional investment.

\section{METHODOLOGY}

In order to determine the stiffness of a particular component and/or assembly, it is, first of all, necessary to identify those components whose stiffness is crucial for the stiffness of the entire constructive framework. Shown in Fig. 1 is an example of a machining system section, where stiffness is analysed for a particular mounting frame element.

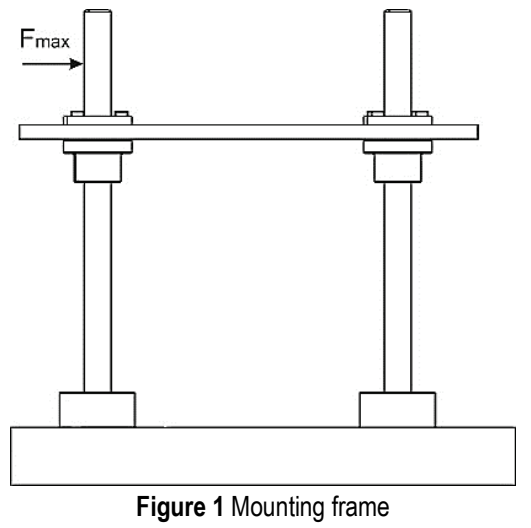

To calculate stiffness, the examined structure is loaded with a force $(F)$, of the magnitude, which increases up to some maximal value $\left(F_{\max }\right)$. During the second stage, the loading force is incrementally decreased, while the displacement of the examined structure is measured under the different force magnitudes. If the cycle is repeated, during next load/unload iterate, a difference will emerge between the new starting load point and the finishing unload point. Therefore, the cycle of loading (solid line) and unloading (dotted line) is repeated several times, until the starting and finishing points are approximately overlapping. In this way, a hysteresis curve is formed, illustrating the dependence between load magnitude $\left(F_{\max }\right)$ and the resulting displacement $(\Delta x)$. Such diagram (Fig. 2) can be constructed for each component which is directly subjected to load.

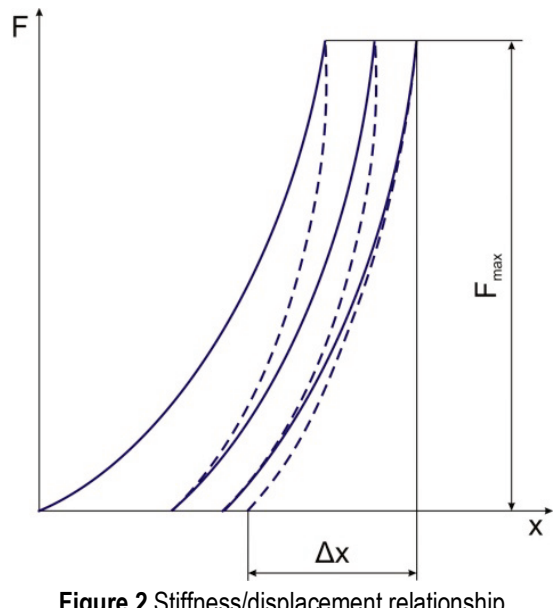

The plan of experiment was to examine the displacement $(x)$ of the cantilevered beam loaded with force $(F)$ on its free end (Fig. 3). The cantilever beam has a round cross-section, and during experiment, stiffness enhancing elements shall be added to it, one at a time. Stiffness enhancing element is block-shaped, with a central opening which allows mounting on the element. The goal is to determine how the enhancing element impacts the stiffness of element.

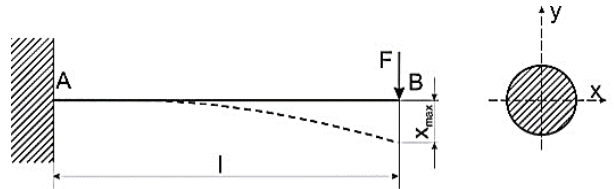

a)
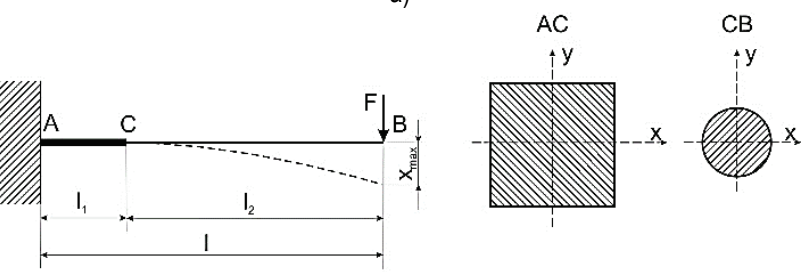

b)

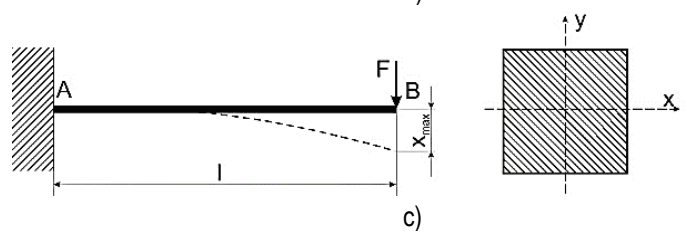

Figure 3 Plan of experiment

a) element with circular cross-section, b) element with variable cross-section, c) element with rectangular cross-section

When considering the impact of enhancing element on the element stiffness, it is possible to discern between three characteristic cases: 
- In the first case (Fig. 3a), one considers the deflection of element with a specified length $(l)$ and a circular cross-section, under influence of a specified force $(F)$.

- In the second case (Fig. 3b), one considers the deflection of element with a specified length $(l)$ and a circular cross-section, under the influence of a specified force $(F)$. On that element, stiffness enhancing elements are being added one-by-one. That changes the geometry of its cross-section. By adding additional stiffness enhancing elements on a specified length $\left(l_{l}=\mathrm{AC}\right)$, the cross-section of the element transforms into rectangular profile, while the remaining length $\left(l_{2}=\mathrm{BC}=l-l_{1}\right)$ preserves the circular profile.

- In the third case (Fig. 3c), one considers the deflection of element with a specified length $(l)$ and a rectangular cross-section, under the influence of a specified force $(F)$. More precisely, in this case, stiffness enhancing elements were placed along the entire length of the considered element, thus changing its cross-section from circular to rectangular.

\section{RESULTS}

\subsection{Numerical Simulation}

Numerical simulation of the element's neutral line was performed by finite element analysis (FEA).

a)

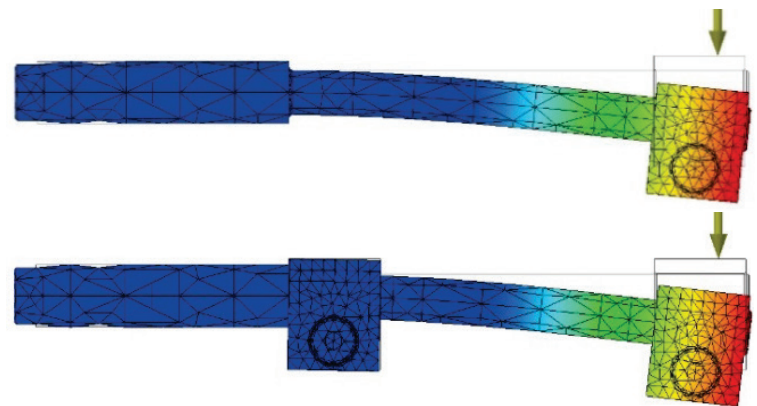

c)

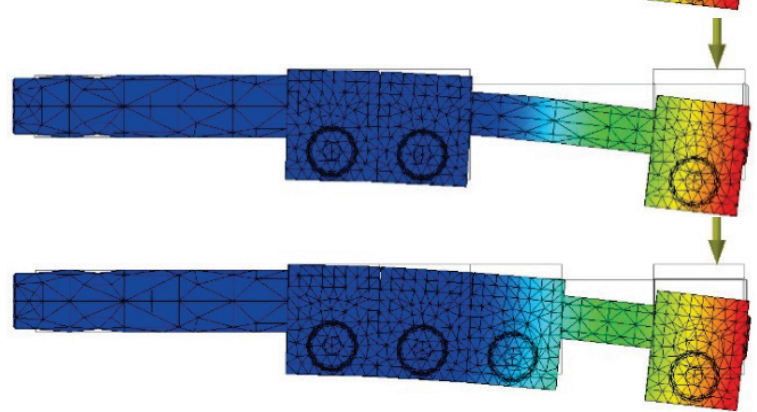

$\downarrow$

e)

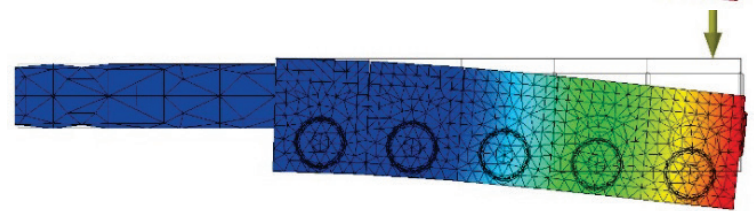

Figure 4 Displacements obtained by FEA

a) with no stiffness enhancement, b) with a single stiffness enhancing element, c) with two, d) three, and e) four stiffness enhancing elements

The analysis included force magnitudes $F=45,57,69$, 81,92 , and $104 \mathrm{~N}$. The material for pillar and stiffness enhancing elements was stainless steel $\mathrm{C} 45$, with the following chemical composition: $0.42-0.5 \mathrm{C} \%,<0.40$
Si \%, $0.5-0.8 \mathrm{Mn} \%,<0.045 \mathrm{~S} \%,<0.045 \mathrm{P} \%,<0.40$ $\mathrm{Cr} \%$, and $<0.43 \mathrm{Ni} \%$. Mechanical and physical characteristics were the following: Young modulus $E=193 \mathrm{GPa}$, Poisson ratio $m=0.3$, and density $q=7.92$ $\mathrm{g} / \mathrm{cm}^{3}$.

Force $(\mathrm{N})$

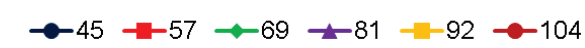

a)
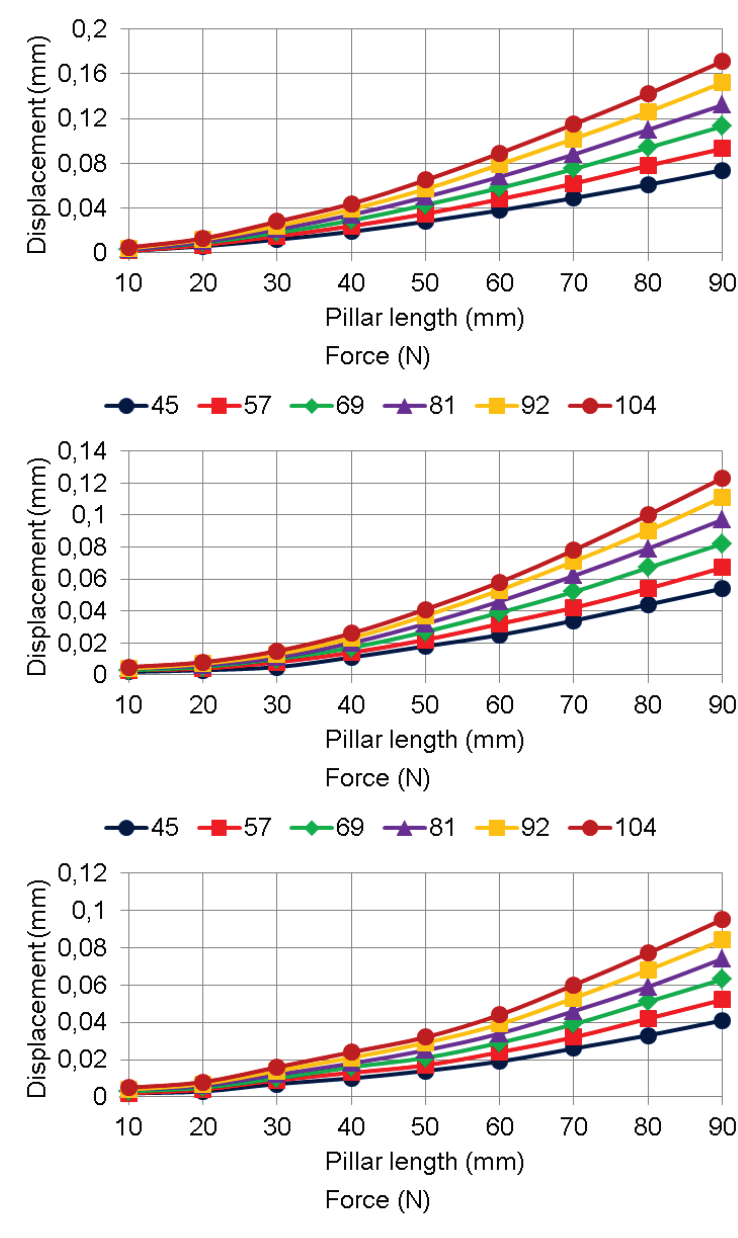

c)

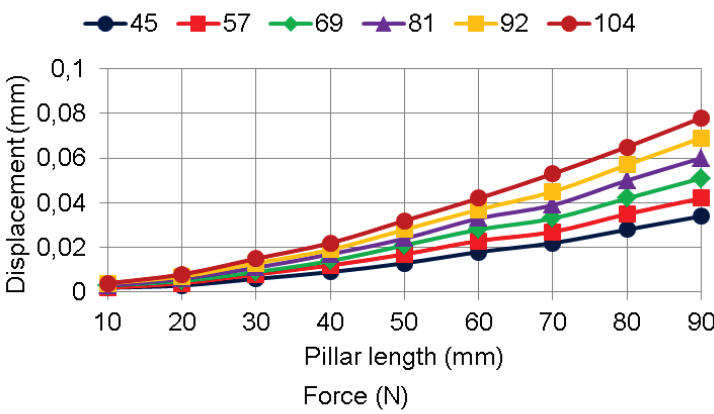

$\rightarrow-45 \multimap-57 \multimap-69 \multimap 81-92 \multimap-104$

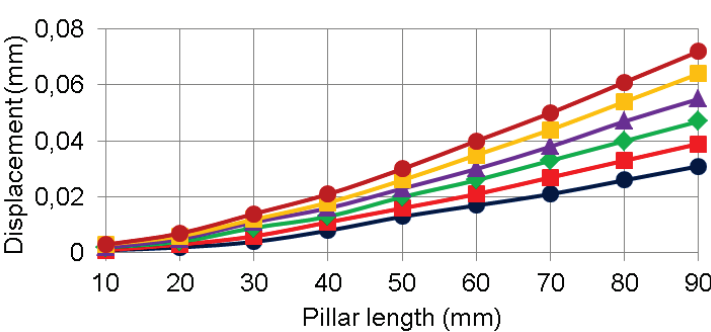

Figure 5 Pillar displacements, depending on the number of applied stiffness enhancing elements, for various force magnitudes

a) with no stiffness enhancement, b) with a single stiffness enhancing element, c) with two, d) three, and e) four stiffness enhancing elements 
The model was meshed using tetrahedral finite elements with four nodes. The size of finite elements was $2 \mathrm{~mm}$, with a refinement of $0.1 \mathrm{~mm}$ in the contact interface zone. Boundary conditions were set to disable displacement in all directions for the element whose stiffness was investigated. Such boundary condition was introduced to keep in place the entire assembly consisting of pillar and stiffness enhancing elements, and prevent translation and rotation of the assembly.

During the simulation, the cross-section of the element was varied through addition of stiffness enhancing elements. Initial simulation was conducted without stiffness enhancement. Each of the succeeding simulations included an additional stiffness enhancing element. A maximum of five stiffness enhancing elements was employed for simulation.

Shown in Fig. 4 are examples of displacements obtained by FEA, under the force of $F=45 \mathrm{~N}$, with the number of stiffness enhancing elements starting from zero to five. Coordinates of FEA elements nodes were used for graphical representation of neutral lines of elements. Fig. 5 shows numerical values of displacements for various lengths of elements, various force magnitudes, and various numbers of stiffness enhancing elements, obtained by FEA.

\subsection{Experimental Investigation}

The principle of experimental investigation conducted in this study is shown in Fig. 6.The mechanical device which generates force $(F)$ consists of a lever (1), calibrated weights (2), and lever mechanisms (3) which allow load transfer onto the element (4) whose stiffness is under examination. Lever's centre of gravity coincides with the centres of the weights, which are gradually added (one, prior to each experiment). The lever is supported at one end by a radial-axial bearing which enables the lever to rotate. At the other end of the lever, there is a ball (5) which transfers the force onto the element under examination. The weights are calibrated to produce forces, which are identical to those simulated by FEA
(Tab. 1). It should be noted that when the weight mass equals $0 \mathrm{~kg}$, load $F$ results from the mass of the lever mechanism. To calculate loads $(F)$ for weight masses ranging between 2 and $10 \mathrm{~kg}$, the mass of the lever which supports weights was taken into account. During the experiment, the cross-section of the element was varied through addition of stiffness enhancing elements. The sequence of experiment executions is shown in Fig. 7. Each experimental test demanded a fresh loading of the pillar, using force values given in Tab. 1. In order to facilitate supporting of the ball on the pillar, a single stiffness enhancing element was mounted at one end of the element, to mark the initial position. In each consecutive experiment, another stiffness enhancing element was added. The goal of experimental tests was to quantify displacements and compare neutral lines of elements with and without stiffness enhancing elements.

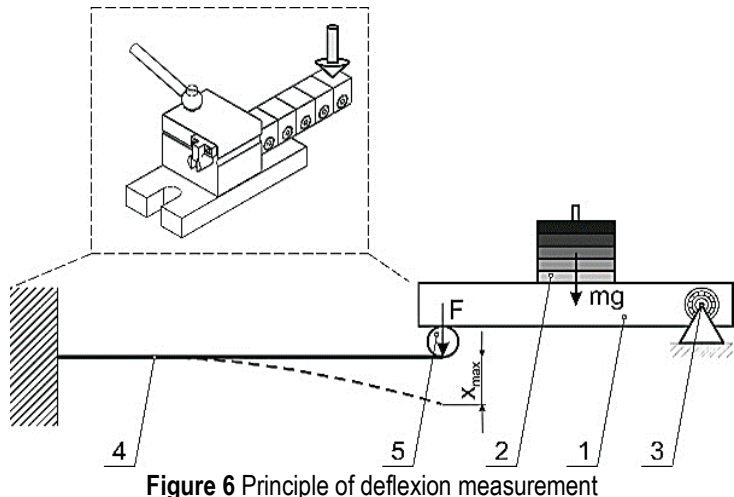

Table 1 Force magnitudes depending on the lever's and weights' masses

\begin{tabular}{|c|c|c|}
\hline Element & $m / \mathrm{kg}$ & $F / \mathrm{N}$ \\
\hline Lever & 6.3 & 45 \\
\hline Weight 1 & 2 & 57 \\
\hline Weight 2 & 4 & 69 \\
\hline Weight 3 & 6 & 81 \\
\hline Weight 4 & 8 & 92 \\
\hline Weight 5 & 10 & 104 \\
\hline
\end{tabular}
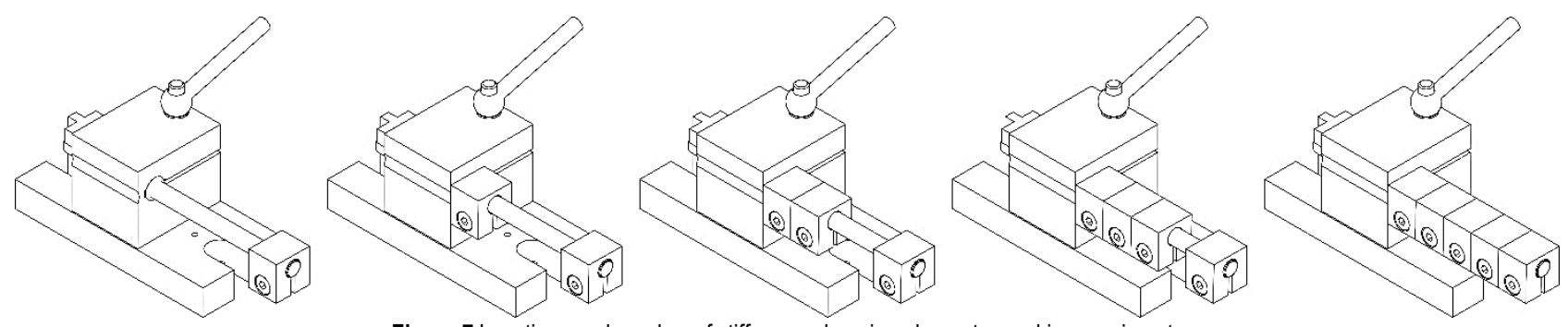

Figure 7 Locations and number of stiffness enhancing elements used in experiments

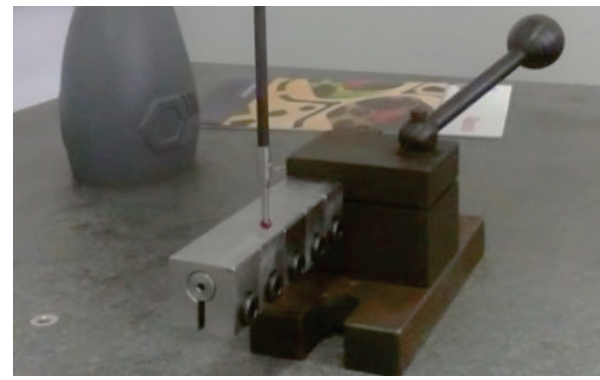

Figure 8 Pillar with stiffness enhancing elements, mounted on a fixture

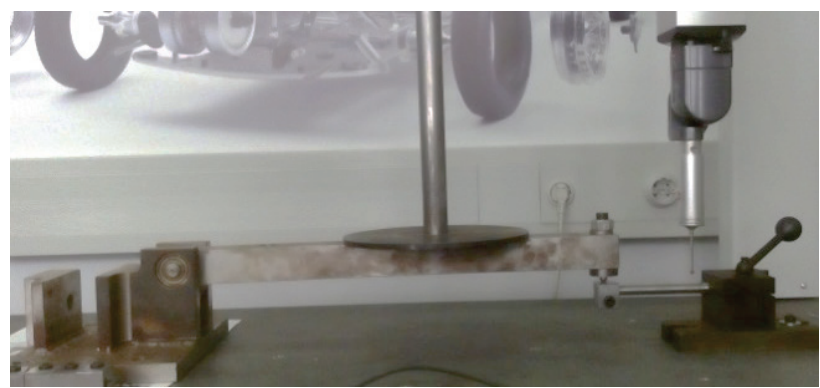

Figure 9 Method of displacement measurement 
During execution of experiments, the element tested for stiffness was located and clamped in a fixture (Fig. 8). Displacements were measured on a coordinate measuring machine, DEA Global Performance (Fig. 9). Values of displacements, measured for various lengths of elements, various force magnitudes, and various numbers of stiffness enhancing elements, are given in Fig. 10.

a)
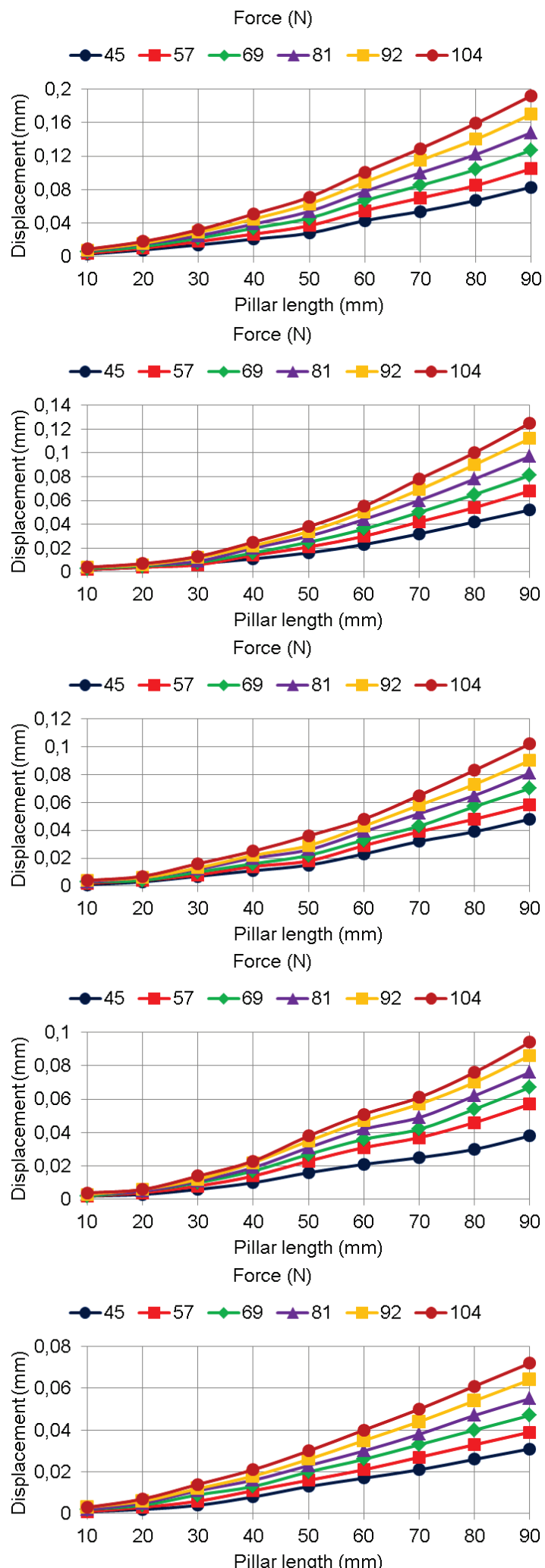

Figure 10 Pillar displacements, depending on the number of applied stiffness enhancing elements, for various force magnitudes

a) with no stiffness enhancement, b) with a single stiffness enhancing element,

c) with two, d) three, and e) four stiffness enhancing elements

\section{DISCUSSION}

Analysis of diagrams shown in Fig. 5 and Fig. 10, indicates satisfactory conformity between numerical simulation and experimental investigation. In both cases, there is an evident trend of increase in displacements, i.e., reduction of stiffness, which follows the increase in length of the tested element and the magnitude of loading force. In all cases, maximal deflection is present in elements of circular cross-section, i.e., without the presence of stiffness enhancing elements which change cross-sectional geometry along a section or along the entire element. The addition of stiffness enhancing elements reduces deflection. Moreover, the deflection is smallest for the shortest segment length and smallest loading force. Conversely, maximum deflection is related to maximum element length and maximum loading force. Given the same loading force, the deflection drops off with the reduction of element length, and the increase in the number of stiffness enhancing elements. Given the same element length, the deflection drops off with the reduction of force, and the increase in the number of stiffness enhancing elements. Expressed in percentages, the results of FEA indicate that stiffness enhancement reduces deflection in the range of $41-52 \%$, while the experimental tests showed the reduction of $42-54 \%$. Based on the numerical and experimental results, it is possible to conduct comparative analysis of the neutral lines under load. According to results shown in Fig. 5 and Fig. 10, for the element with circular cross-section, there are very small deviations between deflection values at both end points for FEA and experimental results. The deviations between the results offered by the two methods are $1-3 \%$, on average, while in the worst case, which occurs in just a couple of points, the deviation equals 10 $\%$. Thus, the observed deviations between results obtained by FEA and experimental procedure are negligible. The deviations can be attributed to complexity of the problem, bearing in mind that the tested element did not have constant cross-sectional area during numerical simulations and experiments. Except in the boundary cases (element with zero stiffness enhancement and element with stiffness enhancement along its entire length), the element has a variable cross-section, partly rectangular, and partly circular.

\section{CONCLUSION}

The conducted investigations allowed insight into the influence of various load force magnitudes on the behaviour of a single element, as well as the entire construction. During experiments, all controllable factors were monitored. Controllable variables in this experiment were element material, load magnitude, reliability and accuracy of the measuring instrument. The dependent variable was the neutral line of the tested element, i.e., the element stiffness. Results of numerical analyses and experimental investigation lead to conclusion that the addition of an adequate number of stiffness enhancing elements can significantly increase stiffness of the very element and the constructive framework as well. The stiffness enhancing elements are of simple construction, 
thus their manufacture does not burden the overall costs, while their application significantly improves stiffness.

Further investigation should be directed towards examination of the behaviour of elements made of various engineering materials, with various cross-sectional geometries. In addition, further efforts shall be focused on examination of dynamic stiffness of elements and constructions. More precisely, stability under oscillations due to time dependent forces. Bearing in mind that analytical methods are unable to fully quantify all factors of influence, research should also be aimed at a more thorough experimental investigation of the nature of oscillation of elements and constructions.

\section{REFERENCES}

[1] Dantan, J. Y., Ballu, A., \& Mathieu, L. (2008). Geometrical product specifications - model for product life cycle. Computer-Aided Design, 40(4), 493-501. https://doi.org/10.1016/j.cad.2008.01.004

[2] Ramesh, R., Mannan, M. A., \& Poo, A.N. (2000). Error compensation in machine tools - a review. Part I: Geometric, cutting-force induced and fixture-dependent errors. International Journal of Machine Tools \& Manufacture, 40(9), 1235-1256. https://doi.org/10.1016/S0890-6955(00)00009-2

[3] Kono, D., Nishio, S., Yamaji, I., \& Matsubara, A. (2015). A method for stiffness tuning of machine tool supports considering contact stiffness. International Journal of Machine Tools \& Manufacture, 90, 50-59. https://doi.org/10.1016/j.jimachtools.2015.01.001

[4] Prasad, K. \& Chakraborty, S. (2016). A knowledge-based system for end mill selection. Advances in Production Engineering \& Management, 11(1), 38-48. https://doi.org/10.14743/apem2016.1.206

[5] Tadic B., Todorovic P., Novkinic B., Buchmeister B., Radenkovic M., Budak I., \& Vukelic D. (2015). Fixture Layout Design Based on a Single Surface Clamping with Local Deformation. International Journal of Simulation Modelling, 14(3), 379-391. https://doi.org/10.2507/IJSIMM14(3)1.280

[6] Simunovic, G., Svalina, I., Simunovic, K., Saric, T., Havrlisan, S., \& Vukelic, D. (2016). Surface roughness assessing based on digital image features. Advances in Production Engineering \& Management, 11(2), 93-104. https://doi.org/10.14743/apem2016.2.212

[7] Todorovic, P., Vukelic, D., Tadic, B., Veljkovic, D., Budak, I, Macuzic, I., \& Lalic, B. (2014). Modelling of dynamic compliance of fixture/workpiece interface. International Journal of Simulation Modelling, 13(1), 54-65. https://doi.org/10.2507/IJSIMM13(1)5.254

[8] Salgado, M. A., De Lacalle, L. N. L., Lamikiz, A., Munoa, J., \& Sanchez, J. A. (2005). Evaluation of the stiffness chain on the deflection of end-mills under cutting forces. International Journal of Machine Tools \& Manufacture, 45(6), 727-739. https://doi.org/10.1016/j.jimachtools.2004.08.023

[9] Agapiou, J. S. (2005). A methodology to measure joint stiffness parameters for toolholder-spindle interfaces. Journal of Manufacturing Systems, 24(1), 13-20. https://doi.org/10.1016/S0278-6125(05)80003-2

[10] Zheng, Y., Rong, Y., \& Hou, Z. (2008). The study of fixture stiffness part I: A finite element analysis for stiffness of fixture units. International Journal of Advanced Manufacturing Technology, 36(9-10), 865-876. https://doi.org/10.1007/s00170-006-0908-5

[11] Zheng, Y., Hou, Z., \& Rong, Y. (2008). The study of fixture stiffness - Part II: Contact stiffness identification between fixture components. International Journal of Advanced Manufacturing Technology, 38(1-2), 19-31. https://doi.org/10.1007/s00170-007-1077-x

[12] Feng, P. F., Yu, D. W., Wu, Z. J., \& Uhlmann, E. (2008). Jaw-chuck stiffness and its influence on dynamic clamping force during high-speed turning. International Journal of Machine Tools \& Manufacture, 48(11), 1268-1275. https://doi.org/10.1016/j.ijmachtools.2008.03.002

[13] Mei, D., Yao, Z., Kong, T., \& Chen, Z. (2010). Parameter optimization of time-varying stiffness method for chatter suppression based on magnetorheological fluid-controlled boring bar. International Journal of Advanced Manufacturing Technology, 46(9-12), 1071-1083. https://doi.org/10.1007/s00170-009-2166-9

[14] Matsubara, A., Tsujimoto, S., \& Kono, D. (2015). Evaluation of dynamic stiffness of machine tool spindle by non-contact excitation tests. CIRP Annals - Manufacturing Technology, 64(1), 365-368. https://doi.org/10.1016/j.cirp.2015.04.101

[15] Tadic, B., Randjelovic, S., Todorovic, P., Zivkovic, J., Kocovic, V., Budak, I., \& Vukelic, D. (2016). Using a highstiffness burnishing tool for increased dimensional and geometrical accuracies of openings. Precision Engineering, 43,335-344. https://doi.org/10.1016/j.precisioneng.2015.08.014

[16] Tadic, B., Todorovic, P. M., Luzanin, O., Miljanic, D, Jeremic, M.B., Bogdanovic, B., \& Vukelic, D. (2013). Using specially designed high-stiffness burnishing tool to achieve high-quality surface finish. International Journal of Advanced Manufacturing Technology, 67(1-4), 601-611. https://doi.org/10.1007/s00170-012-4508-2

[17] Shi, Y., Zhao, X., Zhang, H., Nie, Y., \& Zhang, D. (2016). A new top-down design method for the stiffness of precision machine tools. International Journal of Advanced Manufacturing Technology, 83(9-12), 1887-1904. https://doi.org/10.1007/s00170-015-7705-y

[18] Gao, X., Li, B., Hong, J., \& Guo, J. (2016). Stiffness modeling of machine tools based on machining space analysis. International Journal of Advanced Manufacturing Technology, 86(5-8), 2093-2106. https://doi.org/10.1007/s00170-015-8336-z

[19] Barbato, G., Genta, G., Cagliero, R., Galetto, M., Klopfstein, J.M., Lucca, A. D., \& Levi, R. (2017). Uncertainty evaluation of indentation modulus in the nanorange: Contact stiffness contribution. CIRP Annals Manufacturing Technology, 66(1), 495-498. https://doi.org/10.1016/j.cirp.2017.04.060

[20] Archenti, A. \& Nicolescu, M. (2017). A top-down equivalent stiffness approach for prediction of deviation sources in machine tool joints. CIRP Annals Manufacturing Technology, 66(1), 487-490. https://doi.org/10.1016/j.cirp.2017.04.066

[21] Liao, J., Zhang, J., Feng, P., Yu, D., \& Wu, Y. (2017). Identification of contact stiffness of shrink-fit tool-holder joint based on fractal theory. International Journal of Advanced Manufacturing Technology, 90(5-8), 2173-2184. https://doi.org/10.1007/s00170-016-9506-3

[22] Matejic, M., Tadic, B., Lazarevic, M., Misic, M., \& Vukelic, D. (2018). Modelling and simulation of a novel modular fixture for flexible manufacturing system. International Journal of Simulation Modelling, 17(1), 1829. https://doi.org/10.2507//JSIMM17(1)407 


\section{Contact information:}

Branko TADIC, Dr. Sc.

University of Kragujevac, Faculty of Engineering

Sestre Janjic 6, Kragujevac, Serbia

Marija MATEJIC, Dr. Sc.

University of Kragujevac, Faculty of Engineering

Sestre Janjic 6, Kragujevac, Serbia

Goran SIMUNOVIC, Dr. Sc.

Josip Juraj Strossmayer University of Osijek,

Mechanical Engineering Faculty in Slavonski Brod

Trg Ivane Brlic Mazuranic 2, 35000 Slavonski Brod, Croatia

Milan KLJAJIN, Dr. Sc

Josip Juraj Strossmayer University of Osijek

Mechanical Engineering Faculty in Slavonski Brod

Trg Ivane Brlic Mazuranic 2, 35000 Slavonski Brod, Croatia

Vladimir KOCOVIC, MSc

University of Kragujevac, Faculty of Engineering

Sestre Janjic 6, Kragujevac, Serbia

Bojan BOGDANOVIC, Dr. Sc.

University of Kragujevac, Faculty of Engineering

Sestre Janjic 6, Kragujevac, Serbia

Djordje VUKELIC, Dr. Sc

University of Novi Sad, Faculty of Technical Sciences

Trg Dositeja Obradovica 6, Novi Sad, Serbia

vukelic@uns.ac.rs 